\title{
From bench to bedside: ways and steps of drug discovery
}

\author{
Ş.Ş. Alkan \\ Basel, Switzerland; UMDNJ, R.W. Johnson Medical School, Department of Molecular Genetics \\ \& Microbiology, Piscataway, NJ, USA
}

\section{Introduction}

For the public two things are not easy to understand about drugs: a) Why drugs are so expensive? b) Why there are only so few new drugs discovered despite higher investments every year. Usually it takes 1015 years to develop a drug. ${ }^{1-2}$ Here, I will guide you through all stages of classical drug development so that you can understand the reasons of the current situation. Although I am not an expert in hematological diseases, the lessons I have learned during my 30 years of experience in the pharmaceutical industry will hopefully prepare you to find novel ways for the treatment of thalassemia.

\section{Preclinical phase}

There are several ways to discover drugs: For example one can follow folk medicine (e.g. aspirin); serendipity (e.g. desferal); whole animal screening (e.g. cyclosporin); cellular screening (many) and rational design-molecular screening (e.g. gleevec). More than half of all new drugs in the US are derived from natural products. This is because Mother Nature makes complex compounds (cyclosporin, taxol etc). Today, chemists can make libraries of thousands of simple but not complex molecules.

Today's drug discovery process which may have 8 steps, starts with a disease hypothesis, that is, we have to have a good idea about the biology of a disease. This helps to identify a molecular target. By developing and using an appropriate test, we can screen a huge number of compounds from the chemical library by means of modern robotic systems. First, we should find hits which may become leads for the medicinal chemist. They then optimize the leads and help to select candidate drugs so that preclinical pharmacology can start (early-ADME, animal models, toxicology etc.). If successful, it will enter into the clinic.

Correspondence: Ş.Ş. Alkan, Mittlere Strasse 8, 4056 Basel, Switzerland http://www.alkanconsulting.com; UMDNJ, R.W. Johnson Medical School, Dept. Mol. Genetics \& Microbiology, Piscataway, NJ, USA.

Key words: thalassemia, drug safety.

(c) Copyright S.S.S. Alkan, 2011

Licensee PAGEPress, Italy

Thalassemia Reports 2011; 1(s2):e29

doi:10.4081/thal.2011.s2.e29

This article is distributed under the terms of the Creative Commons Attribution Noncommercial License (by-nc 3.0) which permits any noncommercial use, distribution, and reproduction in any medium, provided the original author(s) and source are credited.

Parts of this work were presented at the "12th International Conference on Thalassemia and Hemoglobinopathies", Antalya (Turkey), 11-14 May 2011.

\section{Clinical phase}

In Phase I clinical trials, researchers test a new drug or treatment in a small group of people (i.e. 20-80) for the first time.The aim is to test safety, dosage range, and identify side effects. In Phase II clinical trials, the drug is given to a larger group of people (100-300). The aim is to test proof of concept (POC) and to further evaluate its safety. In Phase III studies, the study drug is given to large groups of people $(1,000-3,000)$. The aim is to confirm its effectiveness, monitor side effects, compare it to commonly used treatments, and collect information that will allow the drug to be used safely. In Phase IV studies, (the post marketing studies) the aim is to delineate additional information including the drug's risks, benefits and optimal use.

The whole drug R\&D may take $10-15$ years and cost $1 / 2-1$ billion dollars. Any drug may die at any stage. Thus, drug discovery is a very risky business. Here we can utilize an algorithm that is based on long-term experience, to prevent costly, early mistakes. This involves systematic analysis of the facts at each step of drug discovery and monitoring the progress in an independent manner. By this method, we support projects that have a high chance of success.

\section{Thalassemia treatment}

1. Iron chelation: Since there are excellent reviews on this standard therapy $3-5$, I will briefly touch upon the status of new treatments.

2. Blood and Marrow Stem Cell Transplants: Allogeneic hematopoietic stem cell (HSC) transplantation is currently the only cure, ${ }^{6,7}$ but is limited by donor availability, regimen-related toxicity and mortality. To prevent problems, the donor's stem cells should match yours as closely as possible (HLA tissue typing).

3. Inserting normal Hb gene into BM stem cells: There are major changes in the field since the incidents of leukemia development in XSCID patients after retroviral gene therapy. ${ }^{8-11}$ Because of the risk of oncogenesis most of the efforts focus now on the lentiviral therapies. Most advanced vector systems do not have enough safety yet. Additional features need to be studied such as conditional expression of the transgene, cell type-specific expression, targeted local administration etc.

4. Triggering a person's fetal hemoglobin: This process intensively studied. ${ }^{12-14}$ Embryonic, fetal, and adult Hbs are sequentially expressed. Understanding the loss of fetal $\mathrm{Hb}$ expression and activation of adult globin could potentially lead to new therapeutic approaches. $\mathrm{HbF}$ is expected to ameliorate the clinical manifestations of $\beta$-thalassemia.

\section{References}

1. Kneller. R. The importance of new companies for drug discovery: origins of a decade of new drugs. Nature Reviews Drug Discovery 2010;9:867-882.

2. Kaitin KI, DiMasi JA. Pharmaceutical innovation in the $21^{\text {st }}$ century: new drug approvals in the first decade, 2000-2009. Clin Pharmacol Ther. 2011;89:183-8. 
3. Neufeld EJ. Update on iron chelators in thalassemia. Hematology Am Soc Hematol Educ Program. 2010;2010:451-5.

4. Heli H, Mirtorabi S, Karimian K. Advances in iron chelation: an update. Expert Opin Ther Pat. 2011 Mar 30.

5. Zhang B, Donga PZ, Corral M, Sasane M, Miller JD, Pashos CL. Pharmacoeconomic Considerations in Treating Iron Overload in Patients with $\beta$-Thalassaemia, Sickle Cell Disease and Myelodysplastic Syndromes in the US: A Literature Review. Pharmacoeconomics. 2011 Mar 31. doi: 10.2165.

6. Gaziev J, Lucarelli G. Stem cell transplantation for hemoglobinopathies. -Curr Opin Pediatr. 2003;15:24-31.

7. Angelucci E. Hematopoietic stem cell transplantation in thalassemia. Hematology Am Soc Hematol Educ Program. 2010;2010:456-62.

8. Yannaki E, Emery DW, Stamatoyannopoulos G. Gene therapy for $\beta$ thalassaemia: the continuing challenge. Expert Rev Mol Med. 2010;12:e31.
9. Roselli E.A., et al. Correction of $\beta$-thalassemia major by gene transfer in hematopoietic progenitors of pediatric patients. EMBO Molecular Medicine, Wiley- Blackwell, July 2010.

10. Frittoli MC, Biral E, Cappelli B, et al. Bone marrow as a source of hematopoietic stem cells for human gene therapy of $\beta$-thalassemia. Hum Gene Ther. 2011;22:507-13.

11. Yi Y, Noh MJ, Lee KH. Current Advances in Retroviral Gene Therapy. Curr Gene. Ther. 2011 Apr 1. TissueGene, Inc.

12. El-Beshlawy A, Hamdy M, El Ghamrawy M. Fetal globin induction in $\beta$-thalassemia. Hemoglobin. 2009;33:S197-203.

13. Macari ER, Lowrey $\mathrm{CH}$. Induction of human fetal hemoglobin via the NRF2 antioxidant response signaling pathway. Blood. $2011 \mathrm{Apr}$ 4.

14. Wilber A, Nienhuis AW, Persons DA. Transcriptional regulation of fetal to adult hemoglobin switching: new therapeutic opportunities. -Blood. 2011 Feb 14. 